Zieht man von letzterer Formel zwei Atome Wasser ah, so bleibt : $\mathrm{C}_{32} \quad \mathrm{H}_{41} \mathrm{~N} \mathrm{O}_{10}$, welche Formel sich von der Hyocholinsäure durch $\mathrm{C}_{2} \quad \mathrm{H}_{2}$ unterscheidel, oder durch denselben Kohlenwasserstoff, der die Verschiedenheil der flücltigen, felten Säuren $(\mathrm{CH})_{n} \mathrm{O}_{4}$ bedingt. In der That treten aber diese zwei Atome Wasser beim Kochen der Cholsäure mil Salzsäure aus und der hierbei entstehende harzarlige Körper zeigt grofse Aelınliclıkeil in seinem Verhalten mit Hyocholinsäure.

\title{
Ueber die Constitution des Taurins und einen damit isomeren Körper;
} von J. Redtenbacher").

In einer früheren Abhandlung **) habe ich den Scliwefelgehalt des Taurins nachgewiesen. Meine Versuche waren damals noch nicht so weit gedichen, dafs ich mir ein Urtheil über dessèn

*) Zur richtigen Würdigung der Entdeckung der interessanten Verbindung, welche Hr. Prof. Redtenbacher in der obigen Abhandiung beschreibt, glauben wir bemerken zu müssen, dafs die Darstellung derselben einem von uns bereits im Mai 1846 von Hrn. Prof. R. mitgetheilt worden ist, zu derselben Zeit, wo wir uns mit der Untersuchung der Trigensãure (diese Annal. Bd LIX S. 297) und des Thialdins beschäftigten. Die Entdeckung des Hrn. Prof. R. ist demnach ganz unabhängig von unserer Untersuchung; sie hat im (icgentheil dazu beigetragen, das Interesse an unsern Versuchen über die Einwirkung des Scliwefelwasserstoffs auf Aldehydanmoniak zu steigern. Die analytischen Resultate der Untersuchung über schwefligsaures Aldehydammoniak kamen uns crst in April 1847 zu.

**) Dicse Amnal. BJI. LVII S. 170.

D. $\mathrm{H}$. 
Constitution erlauben durfte. Zum Schlusse jener Abhandlung machte ich die Bemerkung, dafs, wenn man Taurin mit Aelzkali oxydirt und die rückständige Salzınasse mit verdünnter Salzsäure zerlegt, sich Schwefelwasserstoff und schweflige Säure entwickelte und sich Schwefel abscheide, als ob man Kali mit reinem Schwefel behandelt hälle.

Diese Reaclion ist es gerade, welche Aufschlufs über die Constitution des Tanrins giebt, wenn man sie auf eine vorsichtigere, woniger stümische Weise anstellt, als ich sie bis dahin angestellt hatte.

Löst man nämlich Taurin in reiner Aetzkalilauge auf und bringt die $\Lambda$ uflösung vorsichtig und allmälig zur Trockene, so kommit ein Moment, in welchem sich reines Ammoniakgas entwickelt. Der ganze Stickstoff des Taurins geht in dieser Periode als Ammoniak fort. Nach einigen Momenten hört die Ammoniakentwickelung wieder auf, und wenn man nun die Reaction unterbricht, indem man die Masse erkalten läfst, so hat man die stickstofffreien Bestandtheile des Taurins als Säuren an das Kali gebunden. Bisher hat keine Schwärzung oder sonstige Veränderung der Kalimasse Stall gefunden, aus der man eine bedeutende Zerslörung der an das Kali gegangenen Verbindung vermulhen könnte.

Zerlegt man die rückständige crkaltete Kalimasse mit verdünnler Schwefelsäure, so entwickelt sich reine schweflige Säure ohne Abscheidung von Schwefel - oder Schwefelwasserstoff, und wird die Flüssigkeil abdestillirt, so crhält man ein Destillat, welches aufser schwefliger Säure noch Essigsäure enthält; in der Retorte bleibt nichts wie schwefelsaures Kali zurück.

Das Destillat habe ich mit Bleihyperoxyd digerirt, die Essigsäure wieder abdestillirt und daraus das Silbersalz dargestellt, welches in allen Eigenschiften mit reinem essigsaurem Silberoxyd übereinstiminte. 
Schon L. Gmelin*) hat vor mehr als zwanzig Jahren in den trockenen Destillationsproducten des Taurins essigsaures Amınoniak nachgewiesen.

Essigsäura, Ammoniak und schweflige Säure sind also dic alleinigen Producte dieser Reaclion. Ueberlegl man sio aber etwas genauer, so enthalten sie den vollkommenen Aufschlufs über die Art und Weise der Anordnung der Elemente des Taurins.

Vorsichtig mit Kali erwärınt, gieht Taurin seinen Schwefel un dasselbe als schweflige Säure ab; diefs beweist, dafs derselbe auch als schweflige Säure im Taurin enthalten war. Denı wäre er als nicht oxydirler Sclıwefel, oder als unterschweflige Säure enthalten gewesen, so hälte sich bei der Zerlegung der Kalimasse neben schwefliger Säure auch Schwefel abscheiden müssen. Wäre er als Schwefelsäure enthalten gewesen, so hälte sich gar keine schweflige Saure entwickeln können und die Gegenwart der Unterschwefelsäure ist durch die zu kleine Anzahl der Atome des Sauersloffs, so wie durch die folgenicu Betrachtungen ausgeschlossen.

Das Taurin enthält also 2 At. schweflige Säure und zieht man ab von Taurin $\quad \mathrm{C}_{4} \quad \mathrm{~N} \mathrm{H}_{7} \mathrm{O}_{6} \mathrm{~S}_{2}$ 2 At. schweflige Säure $\quad \mathrm{O}_{4} \mathrm{~S}_{2}$

so bleiben die Elemente von $\mathrm{C}_{4} \quad \mathrm{~N} \mathrm{H}_{7} \mathrm{O}_{2}=$

Aldehydammoniak über $\quad \mathrm{C}_{4} \mathrm{H}_{3} \mathrm{O}+\mathrm{NH}_{3}+\mathrm{HO}$.

Das Ammoniak ist bei der Reaclion als Gas entwichen und der Aldehyd findet sich durch Kali oxydirt und gebunden als Essigsäure wieder.

Das Taurin ist also saures, schwefligsanres Aldehydammoniak, etwa in eben so verdichtelem Zustande wie cyansaures Ammoniak im Harnsloffe ist.

*) Tiedemann und (jmelin, die Verdaung Bd. I S. 43 - 60). 
Da bisher keine Verbindung bekannt ist, in welcher Aldehydammoniak und schweflige Säure enthalten sind, so würde die so eben aufgestellte Ansicht über die Constitution des Tourins bei manchem Leser der Wahrscheinlichkeit entbehren. Allein es existirt wirklich eine solche Verbindung im loseren Zustande als im Taurin, wieder analog dem cyansauren Aulmoniak.

Löst man Allehydammoniak in Alkohol und leitet schwefligsaures Gas hinein, so erwämt sich die Flüssigkeit bedeutend, während das Gas in grofser Menge absorbirt wirl. Kühlt man die Aldehydlösung gut $a b$, so scheidet sich nach einer Weile, wenn die Flüssigkeit sauer zu reagiren anfängt, eiı weilser krystallinischer Körper in reichlicher Menge ab.

Man kann auch die alkoholische Lösung von Aldehydammoniak mil Alkohol, welcher mit schwefligsaurem Gas gesältigt ist, bis zur sauren Reaction mischen, und es scheidet sich derselbe krystallinische Körper ab.

Er wird auf einem Filter gesammelt, mit starkem Alkohol gewaschen, unter der luftpumpe getrocknet und ist nun schon fast ganz rein, wenn man reines, besonders ammonialifeies Aldehydaminoniak angewandt hat.

Er ist ein weifses, in kleinen prismalischen Nadeln, bei zu starker Erwärmung während der Bereitung, auch in undeullichen Krystallen erscheinendes Salz, von schwachem, aber deutlichem Geschmack nach schwefliger Säure und Aldehydammoniak und von saurer Reaction. An der Luft in trocknem Zustande verändert sich dieses Salz langsam; bei $100^{\circ}$ und Luftzutritl zerlegt es sich, wird gelb, danı bräunlich, verliert bédeutend an Gewicht, wobei sich ein Geruch verbreitet nach verbranntem Taurin.

Die Untersuchung aut scine Zusammensetzung gab folgende Resultate, wobei jeder Versuch mit einer besonders dargestellten Portion vorgenommen wurde : 
I. 0,373 Grın. dieses Salzes gaben 0,261 Grm. Kohlensäure und 0,190 Grm. Wasser.

II. 0,4945 Grm. Substanz gaben 0,352 Grm. Kohlensäure und 0,266 Grm. Wasser.

Ill. 0,3175 Grm. Substanz gaben 0,606 Grm. Platinsalıniak.

IV. 0,2095 Grm. Substanz gaben 0,3935 Grm. schwefelsauren Baryt.

V. 0,6572 Grm. Substanz gaben 1,211 Grm. schwefelsauren Baryt.

IV. 0,395 Grm. Substanz gaben 0,726 Grm. schwefelsauren Baryt.

Diefs entspricht :

berechnet

I. II. III. IV, v. VI. Taurin

4 Aeq. C $300,0 \quad 19,2 \quad 19,08 \quad 19,41 \quad " \quad \Rightarrow \quad " \quad, \quad " \quad 19,28$

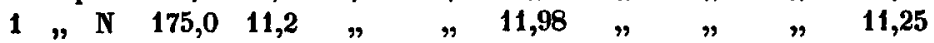

$\begin{array}{lllllllllll}7 & \text { H } & 87,5 & 5,6 & 5,66 & 5,97 & \# & \# & \# & \# & 5,73\end{array}$

6 "

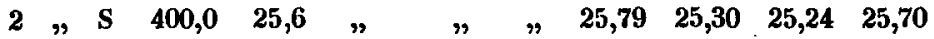

1 , saures $1562,5 \quad 100,0$

schwefligsaures Aldehydammoniak.

Dieses Salz mit der Formel $\mathrm{C}_{4} \mathrm{~N}_{7} \mathrm{O}_{6} \mathrm{~S}_{2}$ ist also isomer mil Taurin, und seine Elemente sind auf dieselbe Weise darin, nur in loserer Verbindung geordnet, es ist in eigentlichem Sinn des Worles saures, schwefligsaures Aldehydammoniak, was auch alle seine Reactionen beweisen. Der Aldehyd ist aber auch darin schon in einem verdichteten Zustande vielleicht als Elaldehyd oder Melaldehyd vorhanden, denn schıweflige Säurc, Anmoniak und Aldehyd, so wie Aldehydammoniak, sind lauter flüchtige Körper, die Verbindung aus allen darin zusanmen ist niclst mehr flüchlig. Erwärmt man sie über der Lampe auf Platinblech, so bräunt und schwärzl sie sich, bläht sich auf, entwickelt einen dem verbrennenden Taurin ähnlichen Gernch und läfst zuletzt eine schwammige Kohle zurück. Erwärmt man sie in einer 
an beiden Enden geschlossenen Röhre bis $100^{\circ}$, so scheint sie sich wenig zu verändern; bis auf $120^{\circ}-140^{\circ}$ erhitzt, wird sie gelblich, beim Oeffnen der Röhre riecht man deullich schweflige Säure. Dieses Salz löst sich in Wasser leicht auf, doch kann es daraus durch Krystallisalion nicht melır leicht erhalten werden. Verdampft man die Auflösung in der Leere, so bilden sich nur wenige Krystalle, der gröfsle Theil bleibt als eine zähe, gummige Masse zurück. In Weingeist ist es elsenfalls, schwer in absolutem Alkohol löslich; die weingeistige Lösung verhält sich beim Verdampfen unter der Luftpumpe ähnlich wie die wässerige Lösung. Destillirt man von einer weingeistigen Lösung den Weingeist theilweise ab, so enthält letzterer schweflige Säure. Als ich eine selır gesätligte Lösung dieses Salzes mit einem Ueberschufs selır starken Alkohols mischte, schied sich am Boden ein dicker syrupartiger Körper ab, ohne Bildung von Krystallen, welche erst nach längerer Zeit ill geringer Menge entstanden.

Es ist mir also nicht gelungen, das saure, schwefligsaure Aldehydammoniak umzukrystalliren. Nur einmal erhielt ich aus einer Mutterlauge, aus welcher die bei der Bereitung entstandenen Krystalle entfernt waren, durch langsames Verdainpfen in einer nicht ganz gut verschlossenen Flasche deutliche prismatische Krystalle. Die obige Schwefelbestimmung, welche den genauesten Schwefelgehalt gab, war mil diesen Kryslallen vorgenornmen.

Verselzt man das Salz mit einer starken Säure, so entwickelt sich schweflige Säure, so wie auch etwas Aldehyd zu riechen ist, ein Ammoniaksalz der Säure bleibt zurück. Mit Kali erhitzl, entsteht eine Reaction, als ob man Aldehyd mit Kali versetzı hätte. Baryt, Blei und Silbersalze gaben mit der Lösung des Salzes Niederschläge, welche theilweilse oder ganz sich in Säuren wieder lösen. Der Niederschlag mit salpetersaurem Silberoxyd, welcher nicht geschwärzt war, zcigte bei nälserer 
Untersuchung nur Spuren eines organischen Körpers und liels beim Yerbrennen selbst melır Silber zurück, als neutrales, sclıwefligsaures Silberoxyd zurückgelassen haben würde.

Alle Versuche, welche ich anstellte, dieses saure, schwefligsaure Aldehydammoniak zu Taurin zu verdichten, milslangen, obwohl Aldehydammoniak und schweflige Säure auf die verschiedenste Weise gemischt wurden, selbst trockener Aldehyddampf mit dem gelben wasserfreien, sauren schwefligsauren Ammoniak von H. Rose zusammengebracht, gab kein Resultat. Vielleicht wird es einem anderen Glïcklicheren gelingen, den Versuch zu erfinden, durch welchen das Salz in Taurin übergeführt wird; vorläufig ist die Kenntnifs des letzteren doch um jenen Schritt vorwärts gebracht, der ein richtiges Urtheil über seine Constitution geslallet.

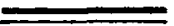 \\ Ueber das Carbothialdin; \\ von J. Redtenbacher und J. Liebig.}

Wenn man reines Aldehydammoniak in Alkohol löst und dieser Flüssigkeit Sclıwefelkohlenstoff zusetzt, so verliert dieselbe sogleich ibre alkalische Reaction, sie erwärnt sich sehr schwach und es scheiden sich nach einigen Minuten sehr glänzende weifse Krytalle ab, welche, mit elwas Alkohol gewaschen, reines Carbothialdin darstellen.

Dieser Körper ist im Wasser und kaltem Aether so gut wie unlöslich, schwer in kaltem, leicht in kochendem Alkohol löslich, und daraus ohne Veränderung krystallisirbar; er stellt eine organische, sauerstofffreie und schwefelhaltige Basis lar, wiewohl der schwächsten Art. 